III.

\title{
Das Wesen der Erbgründe und der Erbfolge nach römischem Rechte.
}

\author{
Von \\ Herrn Geheimrat Dr. Eduard Hölder \\ in Leipzig.
}

Das nach jeder Richtung an Anregungen reiche römische Privatrecht meines. Kollegen Mitteis veranlaßt mich, im bezeichneten Punkte seinen Ausführungen gegenüber meine 1881 in meinen Beiträgen zur Geschichte des römischen Erbrechts und namentlich 1895 in meiner Abhandlung über die Stellung des römischen Erben (in dieser Zeitschrift 16 S. $221 \mathrm{ff}$., sowie als eigne Schrift) dargelegten Anschauungen von neuem zu vertreten und zu begründen.

Mit Mitteis (S. 79) gehe ich aus von der „einheitlichen Gewalt des pater familias" und der Zusammenfassung ihrer Objekte als seiner familia. Nach ihm ist aber "wohl zu beachten", daß diese ursprünglich "die freien Mitglieder des Hauswesens" nicht umfaßte, wofür es genüge, "an die mancipatio familiae oder die $a^{\circ}$ familiae herciscundae zu erinnern". Doch ergeben diese Beispiele jene Beschränkung nur für die familia eines Verstorbenen. Die Ausdrücke pater-, mater-, filius familias bezeichnen nach Mitteis nicht die Stellung im Hause, sondern nur die Stellung zum Hausgute; doch bezeichnet der erste Ausdruck die Stellung als Haupt des Hauses und bezeichnen die zwei andren gerade nicht verschiedne Stellungen zum Hausgute, sondern nur verschiedne persönliche Stellungen im Hause.

Ist entscheidend der Begriff der familia oder des Hauses als des Gebietes der Gewalt des Hausherrn, so liegt nichts näher, als die Zurückführung des Testamentes auf die seinen Tod überdauernde Wirksamkeit seiner Gewalt, auf der es auch beruht, daß die bis zu seinem Tode dieser unterworfnen Menschen, seien sie nun Freie oder von ihm freigelassene 
Sklaven, sich seiner Beerbung nicht entziehen können, während extranei nicht seine Erben werden ohne ihre nach seinem Tode erklärte Zustimmung oder hereditatis aditio. Bedenken wir, daß es im Wesen der hereditas lag, als mit dem Tode des Erblassers eingetreten zu gelten, wenngleich sie in Wirklichkeit erst später eingetreten war, was im Falle der hereditas eines extraneus unerläßlich war, daß daher nur im Falle der Einsetzung eines der Gewalt des Testators unterstehenden domesticus heres sowohl jene Zeit des Fintritts der hereditas als ihr Eintritt kraft des Willens des Testators, wie ihn die Formel: heres esto ausdrückt, eine volle Wahrheit ist, so tritt uns als die ursprünglichste die Erbeinsetzung solcher Menschen entgegen, die in der Gewalt des Testators sind. Von diesem Falle geht auch aus die im Zwölftafelgesetze sich findende Bezeichnung dessen, der keinen testamentarius heres hat, als eines solchen. der intestato moritur oder kein Testament hinterläßt; denn nur wer ein solches Testament hinterläßt, worin er ein Objekt seiner Gewalt zum Erben ernannt hat, ist, falls dieses nicht vor ihm stirbt, seiner testamentarischen Beerbung sicher, die andrenfalls noch von der Zustimmung des Erben abhängt.

Abgesehen von den in seinem Testamente freigelassenen und zu Erben eingesetzten Sklaven, deren Einsetzung nur ein Notbehelf für den Fall der ihm sonst drohenden Erblosigkeit war, sind die von ihm zu Erben eingesetzten Objekte seiner Gewalt identisch mit den sui heredes, die auch seine Erben sind, wenn er kein Testament hinterläßt. Sie sind zugleich die Personen, die er, weil sie ihm am nächsten stehen, regelmäßig am liebsten zu seinen Erben haben will. Der suus und namentlich der Sohn ist es, der den Namen des pater familias trägt und fortpflanzt, und daß den Römern an der Vereinigung dieses Momentes mit der Eigenschaft eines Erben lag, zeigt auch der Umstand, daß einem zum Erben eingesetzten extraneus vielfach auferlegt wurde, den Namen des Testators zu führen. Wenn Cicero (pro P. Quinctio 4) es als Motiv der Erbeinsetzung bezeichnet: ut ad quem summus moeror morte sua veniebat, ad eundem summus honor quoque perveniret, so trifft dieses Motiv vor allem für die nächsten Angehörigen zu. Kommt dazu, daß 
jedenfalls schon in alter Zeit das Testament, um zu Recht zu bestehen, die sui entweder zu Erben einsetzen oder enterben mußte, so kann keine Auffassung des römischen Testamentes richtig sein, nach der ihre Erbeinsetzung, anstatt seinem Wesen gemäß zu sein, diesem vielmehr widersprach. Dies gilt insbesondre von der Auffassung des ältesten Testaments als einer Art von arrogatio, die neuerdings wieder Mitteis vertritt. Nach ihm war "durch Jahrhunderte . . die Kindeserbfolge fast die einzige und jedenfalls die paradigmatische ... und von dem Komitialtestament liegt es auf der Hand, daß es eben nur den Zweck gehabt haben kann, im Weg gesetzlicher Ausnahmebestimmung den Erfolg der Kindeserbschaft genau nachzuahmen". Vom ältesten Manzipationstestament bemerkt er, es sei "schwerer mit dem Prinzip verträglich", aber auch ein bloßer Notbehelf gewesen, neben dem „das Komitialtestament jedenfalls als die eigentliche und richtige Form des vollwirksamen letzten Willens fortdauernd gehandhabt wurde" (S. 100). Wir heben dies hervor als Zeichen, daß nach Mitteis jener allein mögliche Zweck des Komitialtestamentes nicht etwa nur einer verschollenen Urzeit angehörte. In unmittelbarem Anschlusse an diese Bemerkung bezüglich des fortbestehenden Komitialtestamentes rühmt Mitteis "die volle Gedankenschärfe und Konsequenz", die das römische Recht bewiesen habe durch seine Festhaltung, ${ }_{i}^{\text {an }}$ der ursprünglichen und einmal als richtig erkannten Grundidee des Erbrechts durch die Jahrtausende und vielfachen Wandel des einzelnen“. „Denn nur als Wirkung der primären persönlichen Repräsentationsidee sind Sätze zu verstehen wie der von der Inkompatibilität der Delationsgründe oder der Unverlierbarkeit der Erbenqualität." Doch dürfte der zweite Satz sich einfach daraus erklären, daß facta infecta fieri non possunt, wogegen der erste gerade mit der durch Mitteis vertretnen Auffassung des Testaments schwer vereinbar ist. Wäre jede andre Erbfolge eine Nachbildung der Kindeserbfolge und liegt es nicht im Begriff des Kindes, daß keine andren Kinder neben ihm existieren, so ist nicht abzusehen, warum nicht eine durch Testament gegebne JErbfolge zu der durch Gesetz gegebnen hinzutreten könnte. Wenn dann Mitteis noch 
erwähnt, der Erblasser könne seine Repräsentation auf mehrere übertragen, aber nur so, "wie das staatsrechtliche imperium des Königs auf kollegialische Magistrate übertragen worden ist", und in der Weise, daß "partes concursu fiunt", so hat der einzelne collega das imperium nicht pro parte, sondern in solidum, wenngleich mit intercessio des andren, und wo partes concursu fiunt, sind die Teile stets gleiche, weil für jeden die gleiche ihn auf einen Kopfteil beschränkende Konkurrenz des andren besteht, wogegen verschiednen Erben beliebig verschiedne Erbteile übertragen werden können.

Im Gegensatze zu dem von Mitteis angenommenen Zweck des Komitialtestamentes vermutet er auf S. $82 \mathrm{Anm}$. 24, der Rechtszustand zur Zeit der zwölf Tafeln sei der gewesen, daß „die Erbeinsetzung nur auf den Intestaterben lauten“" durfte, „wenn nicht die Komitien eine Abweichung bewilligten“. Danach wäre also schon damals eine Modifikation jenes Zweckes eingetreten. Die Quellen kennen weder jenen Zweck noch die Eigenschaft des Komitialtestamentes als eines Gesetzes. Sie stellen es zusammen mit dem testamentum in procinctu, das keinesfalls ein Gesetz war. Sie bezeichnen die Testamentskomitien als comitia calata, von denen uns Gell. 15, 27 sagt, daß sie stattfanden pro collegio pontificum. Als Gegenstand dieser comitia nennt er neben den Testamenten und der unaufgeklärten sacrorum detestatio Inaugurationen, die keinesfalls Gesetze sind. Fs gibt überhaupt keine Gesetzeskomitien unter pontifikaler Leitung. Mit Unrecht beruft man sich dagegen auf die nach Gell. V, 19 arbitris pontificibus stattfindenden Arrogationskomitien. Die Eigenschaft der pontifices als arbitri bedeutet nicht pontifikale Leitung der Komitien, sondern nur ein ihrer Abhaltung durch die weltliche Obrigkeit, die allein das ius cum populo agendi hat, vorhergehendes pontifikales Gutachten. Die bei diesen Komitien, die auch nicht calata heißen, stattfindende Abstimmung ergibt nicht das gleiche für die Testamentskomitien. War bei diesen, worauf schon der Name des testamentum hinweist, der populus lediglich testis, so findet auch der Unterschied von allen andren der Zeugen bedürfenden Rechtsgeschäften, daß als Zeuge das ganze Volk (be- 
ziehungsweise beim testamentum in procinctu das Heer) fungiert, seine zureichende Erklärung darin, daß nur dadurch für die vielleicht sehr späte Zeit, zu der das Geschäft in Kraft treten wird, die Sicherheit gegeben ist, daß noch Zeugen desselben existieren.

In Beziehung auf den Inhalt des Komitialtestamentes wissen wir nicht nur nichts davon, daß er ein andrer gewesen wäre, als der überhaupt für das römische Testament bezeugte, sondern es ist auch dieser vielfach ein solcher, den das testamentum per aes et libram erst zu der Zeit erlangt haben kann, als die familiae mancipatio ihre sachliche Bedeutung verlor und die sich daran anschließende testamenti nuncupatio einen mit jener nicht verträglichen. Inhalt erhielt, der aus dem älteren Testamente in das testamentum per aes et libram übertragen wurde. ${ }^{1}$ )

Die familiae mancipatio erforderte einen handlungsfähigen und der familia des Testators nicht angehörenden familiae emptor. Dafs der testamentarius heres sowohl handlungsunfähig sein, als namentlich dieser angehören kann, muß aus dem älteren Testamente stammen. Wären die 'Testamentskomitien den Arrogationskomitien wesensgleich gewesen, so hätten sie die Anwesenheit und Zustimmung des heres erfordert und hätte dieser weder impubes noch weiblichen Geschlechts sein können. Keinesfalls aber hätte der testamentarius heres ein suus sein können. Entweder hätte die Existenz eines solchen die Möglichkeit des Testamentes aus-

1) Wenn nach Binder (Die Plebs 1909 S. 353) ,erst das jüngere Manzipationstestament ein letzwilliges Erbeinsetzungsgeschaft im Sinne des klassischen römischen Rechts gewesen sein kann", so ist nicht zu verstehen, wie es ein solches werden konnte, wenn der Inhalt, den es in Widerspruch zu seiner Form hat, nicht anderswoher stammte. Und woher sollte ex sonst stammen, als aus dem Komitialtestamente? Begegnet uns dieser Inbalt nur in Rom, so bleibt freilich die Frage unbeantwortet, wie die Röner auf ibn gekommen sind, was aber nichts daran äudert, daß er nicht erst aus dem Manzipationstestamente stammen kann und ein Teil des für unser Wissen dem römischen Rechte von Anfang an eigenen Inhaltes ist, wie namentlich auch die im Gegensatze zu jedem anderen lechte ihm eigne, scharfe Unterscheidung des ius publicum und privatum und die damit zusammenhängende Unbegrenztheit der potestas des pater familias. 
geschlossen, weil die durch dieses auszufüllende Lücke nicht bestanden hätte, oder, wenn trotzdem die Aufnahme eines extraneus in die familia möglich gewesen wäre, so wäre der testamentarius heres zu den sui hinzugetreten. Wäre von diesem Standpunkte aus beredis institutio eines suus überhaupt nicht möglich gewesen, so hätte die exheredatio eines solchen als eine Art testamentarischer emancipatio der testamentarischen Adoption gegenüberstehen müssen, was weder damit übereinstimmt, daß sie nicht ohne heredis institutio möglich ist, noch damit, daß sie die Agnation ebensowenig aufhebt, wie heredis institutio solche begründet. Auch sie kann aber nicht erst beim testamentum per aes et libram aufgekommen sein.

Der suus heres ist für den Verstorbenen sowohl suus oder Einer der Seinigen als Erbe. Er bildet keinen Gegensatz zum testamentarius heres, der suus nicht sein muß, aber sein kann. Daß es kein gültiges Testament gibt, in dem er nicht entweder zum Erben eingesetzt oder enterbt wäre, widerspricht nicht der durch die zwölf Tafeln gewährleisteten Testierfreiheit, sondern gehört zur Testamentsform, die vom Gesetze ebensowenig bestimmt und ebensosehr vorausgesetzt wurde, wie die Form jedes Rechtsgeschäftes. Wäre das Testament ein Gesetz gewesen, das für den konkreten Fall eine Ausnahme von dem sonst geltenden Gesetze bestimmt, so wäre es selbstverständlich, daß dieses Gesetz insoweit gilt, als nicht jenes eine Ausnahme macht. Dem römischen Testamente ist es aber wesentlich, daß es die Beerbung des Testators vollständig regeln muß. Die Römer haben darin nicht (trotz solcher Ausdrücke, die das Gegenteil andeuten) eine logische, wohl aber eine durch ihr Recht bestimmte Notwendigkeit gesehen. Erklären sie doch, daß ius nostrum non patitur eundem in paganis et testato et intestato decessisse (Pompon. 1.7 D. de reg. iur. 50, 17), so daß jene Notwendigkeit für den miles nicht besteht, für den im Gegensatze zum Bürger zwar rechtliche Schranken, aber nicht die Grenzen des Denkbaren sich beseitigen lassen. Ein die Erbfolge nur zum Teil normierender letzter Wille ist also nach römischer Auffassung nicht etwa undenkbar, aber in der Regel von Rechts wegen unzulässig. Fragen wir, warum, 
so ist leicht verständlich der Ausschluß nur pro parte eintretender Beerbung, der auch für unser Recht dadurch gegeben ist, daß es überhaupt keine Erblosigkeit mehr gibt. Wenn aber verschiedene Erben nebeneinander zu beliebig verschiedenen Teilen erben und auch in verschiedner Weise mit Vermächtnissen oder Auflagen beschwert sein können, so scheint kein Hindernis zu bestehen für die ja auch durch das römische Recht dem miles gegebne Erlaubnis, dem Gesetze die Verfügung über die Erbfolge zwar nicht ganz, aber doch zum Teile zu überlassen. Ist anderen Bürgern die eigne Regelung ihres Nachlasses nur als vollständige gestattet, so haben sie zwischen seiner eignen Regelung und seiner Regelung durch das Gesetz zu wählen, das es verschmäht, sich an ihr zu beteiligen, wenn sie nicht in ihrem vollen Umfange ihm überlassen bleibt. Welches auch die Motive dafür gewesen sein mögen, so ergibt sich daraus eine Verschiedenheit der testamentarischen und der gesetzlichen Regelung, die es verbietet, in jener einen Fall dieser zu sehen (vgl. dazu meine Beiträge usw. S. $152 \mathrm{ff}$.).

Wenn die zwölf Tafeln bestimmt haben: uti legassit, ita ius esto, so bezeichnen sie unzweideutig als Subjekt des legare den Testator, und aus der sprachlichen Verwandtschaft des legare mit der lex läßst sich um so weniger die Gesetzesnatur des Testamentes ableiten, da die Auffassung des legatum als einer lex rei suæ dicta das Gegenteil ergibt und der Zwölftafelsatz ausdrücklich von einem legare suæ rei redet. Freilich gibt er sonst genug Anlaß zu Zweifeln. Einesteils haben die Römer die ganze Testierfreiheit auf ihn zurückgeführt. Andrenteils geht auf ihn der Kunstausdruck legatum zurück, von dem, wenn er später sich auf einen Teil des legare im Sinne des Gesetzes zurückgezogen hätte, doch schwer begreiflich wäre, daß er gerade dessen wichtigsten und für das Testament allein wesentlichen Inhalt nicht mełrl bezeichnet hätte. Das Gesetz sprach von legare super pecunia tutelave. Das legare super tutela ist unstreitig eine Spezialverfügung, die tutoris datio. Seine Parallelisierung mit dem legare super pecunia weist darauf hin, daß auch dieses eine solche war. Wäre damit die Erbeinsetzung gemeint, so wäre schwer begreiflich, daß als sein Objekt nicht 
die familia genannt ist, die das Gesetz den ab intestato erbenden Agnaten zuweist. Von der familia könnte die pecunia sich dadurch unterschieden haben, daß jene, aber nicht diese auch unveräußerliche Bestandteile hatte. Als Hauptform der Errichtung von Legaten finden wir noch später die Worte do lego. Als Form der tutoris datio begegnen neben den Worten tutor esto die Worte tutorem do. Auch hier mag es ursprünglich geheißen haben do lego, und so ist es nicht unwahrscheinlich, daß im Sinne des Gesetzes das legare super pecunia tutelave sich gerude auf dieses doppelte dare bezog, das nicht nur als legatum per vindicationem, sondern auch als tutoris datio ein legare suæ rei war, wenn wir einen Bestandteil der sua res auch in den unmündigen sui als solchen sehen, die noch ein Objekt der Verfügung des Verstorbenen waren. ${ }^{1}$ )

Wenn wir das legare des Gesetzes so verstehen, ist sein Begriff enger als der Begriff des testamentum, bezüglich dessen sowohl aus andren Gründen, als wegen der vom Gesetze bestimmten Beerbung dessen, der intestato moritur, durch den proximus adgnatus nicht bezweifelt werden kann, daß es eine heredis institutio erforderte. Daß gleichwohl das Gesetz die Freiheit der Verfügung nur bezüglich des legare besonders bestimmt hat, mag darauf beruhen, da $B$ im Gegensatze zur Macht der Einzelverfügung die Macht der Erbeinsetzung schon zu festgewurzelt war, um besonderer Bestimmung zu bedürfen. Wenn man dann später die ganze Testirfreiheit aus jenen Worten ableitete, war dies ein Argument a maiore ad minus, indem man die sogar jeder Einzelverfügung erteilte Sanktion als eine solche ansah, die um so mehr der Bestimmung über die Erbfolge galt, ohne die eine Einzelverfügung nicht möglich war.

Die in Ermanglung eines Testaments und eines suus heres platzgreifende Erbfolge des proximus adgnatus und der

1) Dies ist. kein Widerspruch dagegen, daß sie durch seinen Tod nicht mehr Bestandteile seiner familia, sondern Subjekte eigner familiæ sind. Während nur die vom Verstorbuen hinterlassne sachliche familia ein Gegenstand der Erbfolge ist, sind doch auch seine unmuindigen Hinterbliebnen ein Gegenstand seiner Verfügung, und sua res ist, was er als möglichen Gegenstand dieser hinterläßt. 
gentiles bezeichnet das Gesetz mit den Worten familiam habe[n]to. Im Erwerbe der familia des Verstorbenen besteht die Universalsukzession des Erben, der als solcher stets eine fremde familia erwirbt. Hätte die testamentarische Erbfolge auf einer Art Adoption beruht, so würde hier der Erbe nicht sowohl eine fremde familia erwerben, als in eine solche eintreten, wie man vom suus heres sagt, dab er die familia, die durch den Erbgang die seinige wird, als eine solche fortsetze, der er schon bisher angehörte. Mit Unrecht betrachtet man aber die zwei Vorgänge, daß der suus durch den Tod des pater familias Subjekt einer eignen familia wird, und daß dessen familia auf ihn übergeht, als identisch. Subjekt einer eignen familia wird er nicht nur als heres, sondern auch als exheredatus. Jiese familia ist abgeleitet von der familia seines bisherigen pater familias. Für sie hat aber dessen Tod nicht die Bedeutung, ihre Existenz zu begründen, sondern nur die Bedeutung, ein bisher vorhandenes Hindernis ihrer Existenz zu beseitigen. Unabhängig von seiner Eigenschaft als dessen Eı be und auch dann, wenn ihn jener von seiner Beerbung ausgeschlossen hat, ist er durch dessen Tod nicht nur sein eigner Herr, sondern auch Herr seiner Ehefrau und seiner Kinder, deren Herr bisher jener war, und soweit dessen Herrschaft über die Seinigen in ihrer Wirksamkeit seinen Tod überdauert, ist sie unabhängig von seiner Beerbung durch diese, denen er auch als von ihm Enterbten Vormünder und durch pupillaris substitutio Erben ernennen kann. Vom Zusammenhang ihrer familia mit der seinigen ist zu unterscheiden der Übergang seiner familia auf sie, dem zwar sie sich nicht entziehen können, den aber er durch die mit ihrer exheredatio verbundene Ernennung andrer heredes ausschließen kann, ohne daß dadurch an jenem Zusammenhange etwas geändert würde. Wie die Familienbeziehung der sui zum Verstorbnen nicht aufgehoben wird durch ihre exheredatio, so wird für extranei keine Familienbeziehung zum Verstorbenen geschaffen durch ihre heredis institutio. Daß jene im Gegensatze zu diesen sich seiner Beerbung nicht entziehen können oder necessarii heredes sind, haben sie mit einem cum libertate zum Erben eingesetzten Sklaven gemein. 
Unterscheidet sich der, sei es kraft Testamentes oder in Ermanglung eines solchen eintretende, Übergang der familia des Verstorbenen auf ein bisheriges Objekt seiner Gewalt vom Übergang seiner familia auf einen extraneus durch die für dessen Eintritt erforderliche hereditatis aditio, so unterscheidet sich auch von der durch das testamentarische heres esto dem extraneus gegebnen Stellung die dem proximus adgnatus durch das familiam habeto des Gesetzes eingeräumte. Jener kann nur die Erbschaft annehmen oder nicht annehmen, die, wenn er sie nicht annimmt, dem nach ihm dazu Berufenen anfällt. Diesem überträgt das Gesetz die Entscheidung über die Fortexistenz der familia des Verstorbnen. Er kann diese nicht nur selbst übernehmen, sondern auch durch in iure cessio einem anderen übertragen, und wenn er weder das eine noch das andre tut, ist, da in legitimis hereditatibus successio non est $^{1}$ ), die Erbfolge ausgeschlossen. ${ }^{2}$ )

1) Für die gentiles hat nach Kar lowa (Röm. Rechtsgesch. II, 882) dieser Satz nicht gegolten. Und allerdings ist er vicht unbedingt gegeben durch die Bedingung ihrer Berufung, daß adgnatus nec escit. Ist doch auch die Bedingung, da $\beta$ der Erblasser intestato moritur, gegen den Wortiaut des Gesetzes erfüllt, wenn er ein Testament hinterläßt, aber keine Erbfolge aus ihm eintritt. Es ist aber nicht abzusehen, warum von den dem Erblasser noch ferner stehenden gentiles nicht gelten sollte, was nach Wegfall des proximus agnatus vom entfernteren gilt. Wie die Bestimmung des Gesetzes namentlich einem Erblasser gilt, der als Weib oder Unmündiger sui und ein Testament nicht hinterlassen kann, so àie Bestimmung bezüglich der gentiles namentlich eiuem solchen, der keine Agnaten haben kann. Wie der Klient und der Freigelassene keine Agnaten hat, aber in gewissem Sinne der gens seines patronus angehört, so mag diese Angehörigkeit namentlich auch für das uneheliche Kind gegenüber der gens seiner Mutter bestanden haben. - ${ }^{2}$ ) Ich sehe ab von der Erbfolge, die in alter Zeit durch usucapio pro herede eingetreten sein soll; s. darüber meine Beiträge S. 129 ff. und ibre Besprechung durch v. Scheurl (Kr. Vjschr. 24 \$. 219), der mit mir darin einig ist, daß Gaius II, 54 eine wirkliche durch usucapio eintretende Erbfolge nicht behauptet, aber mit Recht darauf aufmerksam macht, der Nachlaß könne Objekt der usucapio in derselben Weise gewesen sein, wie der mancipatio. Seine usucapio wäre danach aufgekommen im Gefolge seiner den zwölf Tafeln noch fremden mancipatio und abgekommen im Zusammenhange mit dem Abkommen der realen Bedeutung der familiae mancipatio. 
Auf Familienzusammenhang beruht die Erbfolge der sui, aber nicht so, daß der Erblasser sie nicht ohne dessen Aufhebung durch Testament ausschließen könnte. Die heredis institutio eines extraneus ist eine solche, die weder auf einem Familienzusammenhange beruht, noch einen Familienzusammenhang begründet. Die Stellung des proximus adgnatus ist ein Familienzusammenhang, der sowohl zur eignen Übernahme der Erbfolge als zu ihrer Übertragung durch in iure cessio ermächtigt. Durch ihre eigne Übernahme wird er aber nicht verstärkt; durch ihre Übertragung auf einen Dritten wird für diesen ein solcher nicht begründet, und durch die Unterlassung sowohl der einen als der andren wird zwar die Erbfolge vereitelt, aber der Familienzusammenhang nicht aufgehoben.

Das Gesetz überweist dem proximus adgnatus oder in Ermanglung von Agnaten den Gentilen die Sorge für die Beerbung eines Verstorbnen, der nicht selbst für diese gesorgt hat, was er getan haben kann unmittelbar durch Hinterlassung eines Testamentes oder mittelbar durch Hinterlassung von sui. Daß sie in Ermanglung jener ihn durch ihre Familienbeziehung beerben, schließt weder ihre eigne testamentarische Erbfolge, noch fremde anstatt der ihrigen platzgreifende testamentarische Erbfolge aus, ohne daß durch diese eine Familienbeziehung zum Verstorbnen begründet oder ihre Familienbeziehung zu ihm aufgehoben würde. Ist ihre Erbfolge eine testamentarische, so hat sie gleich fremder keine andre Grundlage als das Testament. Ob sie erben ex testamento oder ab intestato, ändert nichts an der Unabhängigkeit ihrer Erbfolge von ihrem Willen, macht aber für den Erblasser den großen Unterschied, daß nur seine testamentarische Sorge für seine Beerbung ihm eine Geltung seines Willens über seinen Tod hinaus ermöglicht, die sich keineswegs in jener erschöpft, sondern namentlich das von den zwölf Tafeln gewährleistete legare suæ rei umfaßt. Sind die sui zugleich heredes, sei es nun ex testamento oder ab intestato, so unterscheiden sie sich gleich den zu Erben ernannten eignen Sklaven von andren Erben durch ihre Eigenschaft als necessarii heredes; sind sie aber nicht Erben, weil im Testamente andre Erben ernannt und sie enterbt sind, 
so hören sie dadurch doch nicht auf, sui des Testators zu sein oder zu seiner sua res zu gehören, so daß er ihnen auch als von ihm Enterbten Vormünder oder Erben ernennen kann.

Daß kein letzter Wille möglich ist, ohne vor allem die Beerbung des Verstorbenen zu regeln, ist ein vom römischen Recht durch die Zulassung der ohne Testament möglichen Fideikommisse aufgegebener Satz, der aber ursprünglich um so mehr für selbstverständlich gegolten haben muß, da man sonst aus der die Erbeinsetzung nicht erwähnenden gesetzlichen Gewährleistung des legare dessen Möglichkeit ohne jene hätte ableiten müssen. Das legare suae rei ist Verfügung über Gegenstände der Macht des Testators, die dadurch über seinen Tod hinaus wirkt. Die Erbeinsetzung ist keinesfalls nur eine solche Verfügung, da sie auf den Erben nicht nur Rechte, sondern auch Verbindlichkeiten überträgt. Die Übertragung der einen und der andern auf die testamentarischen Erben steht nicht auf derselben Stufe; denn die Übertragung jener kann durch ihre testamentarische Zuwendung an Dritte ausgeschlossen werden, während der Übergang dieser auf die Erben ein notwendiger ist. Daß im Gegensatz zu den Rechten des Verstorbenen, die durch das Testament Dritten zugewendet und dadurch seinen Erben entzogen sein können, seine Verbindlichkeiten in ihrem vollen Umfange auf die Erben übergehen müssen, gilt aber nicht vom einzelnen Erben, auf den sie nur zu seinem Erbteil übergehen, sondern nur von ihrer Gesamtheit. Gingen sie, wie man sagt, auf seine Erben über durch den Übergang seiner Persönlichkeit auf diese, so müßten sie auf jeden Erben voll übergehen. Sie müssen aber in ihrem vollen Umfang nicht auf die einzelnen Erben übergehen, sondern nur durch die Gesamtheit der Erben ihm abgenommen werden. Nur als ein solcher, der vor allem dafür sorgt, daß sie nach seinem Tode ihn oder sein Andenken nicht mehr belasten, kann er irgendwelche letztwillige Verfügungen treffen. Wie er diese trifft als ein nicht mit seinen Erben identischer, sondern sich von ihnen aufs schärfste unterscheidender und durch Zuwendung von Nachlaßbestandteilen an Dritte ihnen jene entziehender, so bedeutet der Übergang seiner Verbindlichkeiten auf seine Erben, daß jene in keiner Weise 
mehr die seinigen sind. Hätte er keine Erben, so könnte es wegen der von ihm hinterlassenen Verbindlichkeiten zu einem sein Andenken belastenden Verkaufe des von ihm hinterlassenen Vermögens durch seine Gläubiger kommen. Durch die Existenz von Erben sind dagegen gleich seinem Vermögen seine Verbindlichkeiten auf andere übergegangen, und dadurch, daß es ihm gelungen ist, Erben zu finden, die ihm seine Verbindlichkeiten abnehmen, ist esihm möglich geworden, auch letztwillige Einzelverfügungen rechtsgültig zu treffen.

Fragen wir, welche Testamentsform die zwölf Tafeln im Auge hatten, so kann sie nur das Komitialtestament und das testamentum in procinctu gewesen sein. Dies ergibt schon der Bericht des Gaius, daß zu diesen das Manzipationstestament accessit, wenn wir bedenken, daß irgendwelche Kunde von Rechtszuständen vor den zwölf Tafeln uns bei den römischen Juristen nie entgegentritt. Dies ergibt aber auch der Inhalt der testamentarischen Verfügungen, der dem testamentum per aes et libram nicht entstammen kann, weil er mit dessen ursprünglichem Inhalt unverträglich ist. Er kann in dieses nur dadurch gekommen sein, daß mit dem Herabsinken der zunächst ein Surrogat der heredis institutio bildenden familiae mancipatio zur bloßen Formalität die ihr folgende nuncupatio testamenti den Inhalt erhielt, den von alters her ein richtiges testamentum hatte. Die familiae mancipatio erfordert ein en der familia der Manzipanten nicht angehörenden familiae emtor; also kann nicht ihr entstammen die Möglichkeit der Erbeinsetzung eines suus, der Einsetzung mehrerer Frben und ihrer Einsetzung zu verschiedenen Erbteilen. Mit ihrer ursprünglichen Bedeutung ist gleich der Erbeinsetzung eines suus die exheredatio eines solchen nicht verträglich. Dasselbe gilt von der für die Erbfolge eines extraneus erforderlichen aditio. Das einen Bestandteil der familia einem Dritten zuwendende legatum war nicht vereinbar mit deren Übertragung auf den familiae emtor, und ebensowenig das obligierende legatum per damnationem, wovon das legatum sinendi modo relictum nur ein Fall ist, wie auch die Worte des Gaius, daß der Testator rogabat, quid cuique post mortem suam dari vellet, nicht einen rechtsverbindlichen Befehl, sondern eine unverbindliche Bitte be- 
zeichnen. Ebensowenig bietet die familiae mancipatio Raum für ein legatum per praeceptionem, während doch die Verteilung verschiedener Nachlaßbestandteile unter seine verschiedenen Angehörigen gewiß einer der nächstliegenden Inhalte des letzten Willens eines Hausvaters ist. Die Erfassung des Komitialtestamentes als einer Art adrogatio hat das Unnatürliche, daß nach ihr gerade ein solches Testament, durch das der Testator lediglich für die Seinigen Bestimmungen trifft, nicht möglich gewesen wäre. Während danach weder ihre Erbeinsetzung noch überhaupt ein nur von ihnen und nicht von einem andren Menschen redendes Testament möglich gewesen wäre, so waren in Wirklichkeit sie die einzigen Menschen, von denen das Testament reden mulite, weil es sie entweder zu Erben ernennen oder enterben mußte. Die Erbeinsetzung war der Hauptinhalt des Testamentes keineswegs notwendig im Sinne des Inhaltes, um den es dem Testator am meisten zu tun war, wohl aber im Sinn eines solchen, ohne den es nicht existieren konnte. Wenn die zwölf Tafeln nicht ihrer, aber des legare besonders gedachten, kann dies seinen Grund darin haben, daß jedes 'Testament, wie sich schon damals von selbst verstand, eine solehe enthalten mußte, während es zweckmäßig schien, ausdrücklich zu bestimmen, welchen Inhalt ein solches außerdem enthalten könne. War die Unmöglichkeit dieses weitren Inhalts ohne jenen primären Inhalt für das Rechtsbewußtsein selbstverständlich, so war es auch richtig, aus der ausdrücklichen gesetzlichen Anerkennung des zweiten abzuleiten, daß um so weniger dem ersten die Anerkennung des Gesetzes fehle.

$\mathrm{Zu}$ den Dingen, für die das testamentum per aes et libram in seiner ursprünglichen Bedeutung keinen Raum bieten konnte, gehört namentlich auch die exheredatio. War sie diesem notwendig ursprünglich fremd, so kann sie doch nicht wohl dem Komitialtestamente fremd gewesen sein. Wäre die heredis institutio eine Art adrogatio gewesen, so wäre die exheredatio eine Art emancipatio gewesen. Trifft in historischer Zeit weder das eine noch das andre zu und müßte die Eigenschaft der Erbeinsetzung als einer durch lex erfolgenden Aufnahme in die familia aus der Zeit vor den 
zwölf 'Tafeln stammen, so wissen wir von einer durch lex erfolgenden Entlassung eines suus aus der familia überhaupt nichts, während die auf andrem Wege erfolgende emancipatio uns berichtet wird als eine auf einen Satz der zwölf Tafeln sich gründende, also erst durch diese möglich gewordene.

Die Nichtigkeit des einen suus weder zum Erben einsetzenden noch enterbenden Testamentes tritt uns in der Überlieferung weder entgegen als eine durch die zwölf Tafeln bestimmte, noch als eine spätere Neuerung. Sie zerfällt in die zwei Arten eines Testamentes, das des suus nicht gedenken konnte, weil er zur Zeit seiner Errichtung nicht existierte, und eines solchen, das eines existierenden suus nicht gedacht hat. Die durch adgnatio postumi eintretende Nichtigkeit eines früher errichteten Testamentes zählt Cicero (de oratore I 57 und pro Caecina 25) zu den causae... eius modi, ut de earum iure dubium esse non possit, und die daher omnino in iudicium vocari non solent. Er bezeichnet es als etwas übcrhaupt nicht Vorkommendes, daß quis eo testamento, quod pater familias ante fecit, quam ei filius natus esset, hereditatem petit. Den Satz adgnascendo rumpi testamentum, der nach ihm dermaßen constat, daß es niemand gibt, der je das Gegenteil behauptet hätte, bezeichnet Cicero damit als einon schlechthin selbstverstänlichen, der, um zu gelten, nic besonderer Bestimmung bedurft hat. 1)aß ihn dagegen Neuere, namentlich A. Schmidt (das formelle Recht der Noterben S. \$) "geradezu eine Durchbrechung des Rechtes der zwölf Tafeln" nennen, ist schon deshalb grundlos, weil die umfassendste Testierfreiheit nicht die Möglichkeit der Vernichtung eines Testamentes durch einen seiner Errichtung nachfolgenden Umstand ausschließt. Wäre freilich das Testament ein die Existenz eines suus begründendes Gesetz gewesen, so wäre nicht abzusehen, warum ein nachgeborner suus nicht einfach zu jenem hinzugetreten wäre. Hat es dagegen nicht diesen Inhalt, ist es ihm aber eigen, jede Erbfolge andrer als der in ihm eingesetzten Erben auszuschließen, so beruht die Einsetzung der bestimmten Erben darauf, daß der Testator sie lieber zu Erben haben will, als jeden Menschen, der sonst sein Erbe sein könnte. Sind nun die Meinigen die Menschen, 
die mir am nächsten stehen, die ich daher nicht nur in Ermanglung eines Testaments als meine Erben hinterlasse, sondern auch in Ermanglung besonderer Gründe für das Gegenteil lieber zu Erben haben will als andere, und wirk das Testament nicht für die Gegenwart, sondern für die ungewisse Zeit des Todes des Testators errichtet, während sein Inhalt sich nur durch die Verhältnisse jener bestimmen kann, so liegt nahe seine Behandlung als eines solchen, das nicht errichtet ist für den Fall der späteren Existenz von sui, die in ihm nicht zu Erben ernannt sind, weil sie zur Zeit seiner Errichtung entweder überhaupt noch nicht oder doch noch nicht als sui des Testators existierten. Die nachträgliche Nichtigkeit des Testamentes führt den Namen der ruptio testamenti gerade nur für die zwei Fälle der mutatio und agnatio, was auf eine Gemeinschaft dieser zwei Vernichtungsgründe hinweist, die darin besteht, $d a ß$ in beiden Fällen das Testament als ein nicht mehr gewolltes gilt. Beruht die ruptio testamenti durch agnatio auf diesem Grunde, so war sie, wann immer sie aufkam, nicht ein Bruch, sondern eine Anwendung der durch die zwölf Tafeln anerkannten Testierfreiheit.

Von der ruptio testamenti durch agnatio eines suus war nur ein Schritt zum Erfordernisse der heredis institutio oder exheredatio vorhandener sui. Es bedeutete nichts andres als die Notwendigkeit einer Erklärung des Testators darüber, ob er sie zu Erben haben wolle. Aus der Bezeichnung seiner Erklärung, daß er sie nicht zu Erben haben wolle, als einer exheredatio folgt nicht, daß dadurch die Eigenschaft eines heres ihnen als eine solche entzogen worden wäre, die sie bereits gehabt hatten. Karlowa (Römische Rechtsgesch. II S. 880) nennt es bedeutsam, daß "die beim Tode des Erblassers zur Sukzession gelangenden sui schon bei dessen Lebzeiten als dessen sui heredes bezeichnet werden." 1) Er sagt, ihre "Erbanwartschaft" könne „ihnen

1) Wie suus heres der suus schon bei Lebzeiten des pater familias als ein solcher heißt, der eventuell dessen Erbe sein wird, so gilt dies von jedem eventuellen heres. So sagt z. B. Cicero pro Quinctio 4: heredem testamento reliquit hunc P. Quintium, während ein extraneus nie schon beim Tode des Testators heres ist. 
zwar durch Testament entzogen werden, aber gerade daraus, daß darin rechtlich eine Entziehung, ein praeterire oder exheredare gesehen wird, ergibt sich das Vorhandensein dieser Erbanwartschaft." Doch ist praeterire weder eine Entziehung noch überhaupt eine Handlung und exheredare eine die Eigenschaft eines heres ausschließende Handlung, die aber nicht diese als eine solche aufhebt, die schon Platz gegriffen hat, da semel heres semper heres. Heißt es doch auch im Fall der Einsetzung cum cretione: nisi ita creveris, exheres esto, während bis zum Ablaufe der Kretionsfrist nicht die Eigenschaft eines heres, sondern nur die Möglichkeit ihres Eintritts durch cretio bestanden hatte.

Wie die exheredatio des suus eine Ausschließung, so ist seine heredis institutio eine Bestimmung seiner Erbfolge, die denselben Inhalt hat wie jede andre Erbeinsetzung. Dafo ihre Wirkung durch die für den suus bestehende Unmöglichkeit, sich der Erbfolge zu entziehen, über die Wirkung andrer Erbeinsetzungen hinausgeht, beruht nicht auf seiner besonderen Eigenschaft als suus, sondern auf seiner ihm mit einem eingesetzten Sklaven gemeinsamen Eigenschaft als Hausuntertan des Testators. Karlowa sagt, durch die Erbeinsetzung des suus werde sein „Erbrecht vielleicht erweitert oder beschränkt, völlig dem eines extraneus gleichgestellt ist es damit nicht, denn immer ist er als einer der sui des Erblassers eingesetzt" (S. 880). Aber "nicht mehr als suus heres, sondern als ein heres ex suis kommt er in Betracht" (S. 887). Was aber für ein Unterschied sein soll zwischen einem suus und einem der sui oder einem suus heres und einem heres ex suis, ist schlechterdings nicht abzusehen. Und wenn, die exheredatio eine Entziehung der Erbanwartschaft wäre, die der suus bei Lebzeiten des pater familias hatte, so müßte es nicht nur eine volle, sondern auch im Falle der Einsetzung zu einem kleineren als dem durch jene Anwartschaft gegebenen Erbteile eine partielle exheredatio geben. In Wirklichkeit gab es eine solche nicht, wie es eine solche nicht geben konnte, wenn die exheredatio nichts andres war, als eine Ausschließung von der Erbfolge.

Ist die exheredatio eine ausdrückliche Ausschließung von der Erbfolge, so erhebt sich um so mehr die Frage, 
warum man diese forderte, da aus der dem Testamente wesentlichen Bestimmung aller Erben die durch dasselbe rollzogne Ausschließung jeder andren als dor durch dasselbe bestimmten Erbfolge folgte. War durch den Ausdruck des Willens, diese Erben zu haben, der Wille ausgedrückt, keine andren Erben zu haben, so konnte es nicht zweifelhaft sein, daß der Testator keine andren Erben haben wollte. Es konnte aber die Frage entstehen, ob nicht Gründe vorliegen, diesen Willen nicht gelten zu lassen, weil er nicht existiert hätte, wenn der Testator an die nicht von ihm genannten sui gedacht hätte. Man kann einen solchen Gedanken für die Zeit, zu der die Notwendigkeit der institutio oder exheredatio der sui aufkam, zu fein finden. Stand aber die ruptio testamenti durch agnatio fest, was sehr früh geschehen sein muß, da sowohl die 'Tatsache der agnatio sehr leicht rorkam als das Bedürfnis, den Nachgebornen nicht leer ausgehen zu lassen, ein dringendes war, so stand dadurch fest, daß das Testament, wie es nur gelten kann, wenn die in ihm Eingesetzten den Testator überleben, so auch nur gilt, wenn diesem nicht sui nachgeboren werden, daß also für das Testament in dieser Beziehung die clausula rebus sic stantibus gilt, deren Annahme vermöge seiner Errichtung für eine ungewisse spätere Zeit hier überhaupt weit näher liegt, als bei anderen für die Gegenwart errichteten Rechtsgeschäften. Stand aber der Ausschluß seiner Geltung durch agnatio solcher sui fest, die der Testator nicht bedenken konnte, weil sie nicht existierten, so lag nahe genug dessen Ausdehnung auf den Fall, daß der Testator einen bereits existierenden suus nicht hatte bedenken können, weil or dessen Existenz nicht kannte. Liegt es doch überall da, wo die clausula rebus sic stantibus gerechtfertigt ist, nahe, einer späteren Änderung der Sachlage eine bercits existierende, aber dem Handelnden nicht bekannte Sachlage gleichzustellen. Und ist doch kaum ein Unterschied zwischen dem Falle, daß dem Testator kurz nach der Errichtung seines Testamentes oder so kurz vor dieser, daß er bei ihr noch nichts davon weiß, ein neuer suus heres ersteht, sei es durch Geburt oder durch den Tod cines andren, dem jene: nachrückt. Wie leicht ist es auch zweifelhaft, ob der eine oder der 
andre Fall vorliegt. Soll es für die Geltung des Testamentes einen Unterschied machen, ob eine Geburt oder ein Todesfall, wovon der Testator bei seiner Errichtung noch nichts gewußt hat, eingetreten ist unmittelbar vorher, unmittelbar nachher oder gleichzeitig, was zu konstatieren vielleicht unmöglich ist? Mit Unrecht plegt man bei der Möglichkeit, daß der Testator von der Existenz eines suus heres nichts weiß, nur an den Fall zu denken, daß er ihn für weggefallen hält. Soll dies zutreffen, so muß er ein Ereignis irrtümlich angenommen haben. Ein weit häufigerer Fall aber ist es, daß er ein Ereignis nicht erfahren hat, wie namentlich den Tod des Sohnes, dessen Kinder er übergangen hat.

Karlowa sagt, (S. 888): "In alter Zeit werden Präteritionen von Hauskindern etwas nicht oder höchst selten Vorkommendes gewesen sein." Wie könnte es aber je etwas nicht oder höchst selten Vorkommendes gewesen sein, daß zur Zeit der Errichtung eines Testamentes der eingesetzte Erbe nicht mehr lebte, wodurch, wenn er zu den sui heredes des Testators gehört, notwendig seine ihm als solche nachrückenden Angehörigen übergangen waren? K. sagt: „Präteritionen aus Gleichgültigkeit werden häufiger gewesen sein und eher eine Abhilfe erheischt haben als irrtümliche." Wie sollen wir uns aber diese Gleichgültigkeit vorstellen? Glaubte man, wie Karlowa meint, der „Gleichgültigkeit der Väter gegen ihre sui heredes" entgegentreten zu sollen, so ist nicht zu verstehen, warum man ihr mehr glaubte entgegentreten zu sollen, als der durch exheredatio sich kundgebenden positiven Abneigung. Und ließ sich die bewußte Übergehung als Gleichgültigkeit auffassen? Wem gleichgültig ist, wer ihn beerbt, der macht kein Testament. Wer in ihm einen ihm bekannten suus übergeht, zeigt dadurch, daß er zu Erben andre und nicht jenen haben will. Daß diese durch den positiven Inhalt des Testaments gegebne Negation besondren Ausdrucks bedarf, beruht darauf, daß dem Testator die Existenz des suus vielleich nicht bekannt war, was ausgeschlossen ist, wenn er poisitiv erklärt, ihn nicht zum Erben haben zu wollen. Freilich könnte seine Kenntnis von der Existenz des suus sich aucih dadurch, daß er desselben im Testament auf andre Weises gedacht hat, oder aus sonstigen 
Gründen ergeben. Daß aber die Wirkung einer Bestimmung über ihren $Z$ weck hinausgeht, ist kein Beweis gegen diesen, und ist um so häufiger, je weiter wir in der Geschichte zurückgehen. Die Form der Rechtsakte ist ein Erfordernis ihrer Gültigkeit, das je länger desto mehr hinter andre zurücktritt, während sie ursprünglich in viel höherem Maße die Bedeutung hat, nicht nur durch ihr Fehlen die Ungültigkeit, sondern auch durch ihr Zutreffen die Gültigkeit des Rechtsakts erkennen zu lassen. Zugleich ist es den Formen des alten Rechts eigen, in der vollen, durch das Herkommen gegebnen Bestimmtheit beobachtet werden zu müssen auch in solchen Stücken, die zur Erreichung ihres Zweckes nicht beitragen. Es spricht daher gegen jenen $Z$ weck des Formerfordernisses der exheredatio weder der Umstand, daß die Versäumung der Form die Goltung des Testamentes auch dann ausschließt, wenn der Testator die Existenz des übergangnen suus gekannt hat, noch der Umstand, dab die Form auch erforderlich ist, wenn jene Kenntnis sich aus dem Testamente selbst als einem der bestimmten Person in andrer Weise gedenkenden ergibt. Jünger als dieses Erfordernis ist die Differenzierung zwischen der Übergehung eines filius und andrer sui. Wie man bei diesen für die mancipatio anstatt des aus den zwölf Tafeln abgeleiteten Erfordernisses dreimaliger mancipatio sich mit einmaliger begnügt hat, so hat man bei ihnen in dem Bestreben, die Nichtigkeit der Testamente wegen Übergehung einzuschränken, sich mit einer exheredatio inter ceteros begnügt, obgleich sie nicht beweist, daß der Testator gerade den bestimmten suus gekannt und bewußt von seiner Beerbung ausgeschlossen hat, und zugleich als Folge ihrer Übergehung anstatt der Nichtigkeit des Testamentes ihren Hinzutritt zu den eingesetzten Exben angenommen. Einesteils hat man sich hier damit begnügt, daß der Testator durch exheredatio inter ceteros ausgedrückt hat, er ziehe seinen sui die von ihm Eingesetzten vor. Andrenteils hat man in Ermanglung einer exheredatio angenommen, er hätte, wonn er an die Existenz der übergangnen sui gedacht hätte, sie den eingesetzten Erben hinzugefügt, also zwar nicht den sui die Eingesetzten, aber auch nicht diesen jene vorgezogen. 
Für postumi konnte diese Erweiterung des Testamentsinhaltes nicht Platz greifen, weil ihre Erbeinsetzung, also auch die bezüglich andrer angenommene stillschweigende Erbeinsetzung nicht möglich war. Und wenn man das Bedürfnis hatte, übergangnen andren sui die eingesetzten Erben gleichzustellen, so hatte man es für den Sohn nicht, der dem pater familias näher steht als jeder andre Mensch. Daß man aber solche übergangne sui, die man den eingesetzten Erben glaubte nicht vorziehen, sondern nur gleichstellen zu sollen, behandelte, wie wenn sie gleichfalls eingesetzt wären, zeigt, da6 man keine grundsätzliche Verschiedenheit zwischen ihnen und eingesetzten Erben annahm. Beruht bei diesen ihre Eigenschaft als Erben, so beruht bei den sui ihre ganze Existenz auf dem Willen des pater familias, dem es in Ermanglung eines von ihm erklärten gegenteiligen Willens auch gemäß ist, $\mathrm{da} B$ sie seine Erben sind. Hätte man vielmehr angenommen, daß sie kraft eignen Rechtes erben, das ihnen zwar durch exheredatio entzogen werden könne, aber im Falle der praeteritio nicht entzogen sei, so wäre es zwar verständlich, dab sie nur neben den Eingesetzten an der Erbschaft teilnehmen, aber nicht, daß sie auch teilnehmen an der diesen durch das Testament auferlegten Belastung. Wenn man die für den Ausschluß der sui von der Erbfolge bestehende Notwendigkeit der exheredatio oder "Entherrung" namentlich auf die Ausführungen des Paulus $(1.11$ de lib. et post. 28,2) gegründet hat, wonach sie vivo patre quodammodo domini existimantur ${ }^{1}$ ), so hat jedenfalls Paulus jene Notwendigkeit nicht darauf gegründet; vielmehr erwähnt er nur die Möglichkeit der exheredatio als etwas dieser Auffassung nicht Entgegenstehendes. Wenn er aber sagt: nec obstat, quod licet eos exheredare, quos et occidere licebat, so zeigt er damit zugleich, wie wenig juristische Wahrheit dieser Auffassung zu-

1) Eingehenderes gegen diese am eindringendsten van Brinz (Pand. 2. Aufl. S. 460) und auch von mir in meinen Beiträgen zux Geschichte des römischen Erbrechts S. $88 \mathrm{ff}$., sowie in dieser Zeitschrift 3 S. $211 \mathrm{ff}$. vertretne Auffassung enthält der vierte Abschnitt meiner Abhandlung über die Stellung des römischen Erben (diese Zeitschrift 16 S. $272 \mathrm{ff}$.). 
kommt. War der pater familias Herr über Leben und Tod der Seinigen, so waren sie in keiner Weiso ihre eigenen Herren, und Teilhaber seiner Herrschaft über sein Vermögen nicht juristisch, sondern nur faktisch dadurch, daß er sie daran teilnehmen lieb. Wie die sui ihm quodammodo domini des Vermögens ihres Vaters sind, so nennt Paulus auch (1. 1 D. de act. r. am. 25, 2) die Ehefrau quodammodo domina des Vermögens ihres Mannes, ohne daß sich hier an irgendwelche juristische Wahrheit dieser Bezeichnung denken ließe.

Wie die Einheit des römischen Hauses kein andres Fundament hat als die Gewalt des Hausherrn, so ist auch diese der Ausgangspunkt der römischen Erbfolge. Nach Mitteis (S. 93) ist das römische Erbrecht beherrscht durch "die Idee des engsten persönlichen Familiennexus zwischen Eltern und Kindern", und er nennt es „einen für das Prinzip durchaus nebensächlichen Umstand", daß im Gegensatze zur adgnatio die bloße cognatio kein Erbgrund war. Sollte aber wirklich dieser Umstand so nebensächlich sein? Nirgends ist der Zusammenhang durch Abstammung greifbarer und enger als im Verhältnisse des Kindes zur Mutter, und doch kennt das älteste uns bekannte römische Recht keine Beerbung der Mutter durch das Kind. Dies läßt sich nicht dwauf zurückführen, daß die Ehefrau wegen der manus des Ehemanns keine Erbschaft hinterlieb. Das Verhältnis zum Vater ist durch seine Ehe mit der Mutter vermittelt. Das Verhältnis. zur Mutter ist ein unmittelbares, und nicht nur hat es in Rom, wie überall, stets uneheliche Kinder gegeben, sondern ein solches war insbesondre noch nach den zwölf Tafeln jedes aus standesungleicher Verbindung hervorgegangne Kind. Keinesfalls also beruhte die Erbfolge des suus heres nur auf seiner Abstammung vom Erblasser, und es ist fraglich, ob sie gleich dessen Gewalt überhaupt auf dieser und nicht vielmehr nur auf der Abstammung ron seiner Ehefrau als einer solchen beruhte, deren Kinder gleich ihr selbst ihm gehören.

Auf die Gewalt des pater familias geht auch die Agnation zurick. Nach Mitteis hat aber in Rom die Agnatenerbfolge "durch Jahrhunderte" nur eine geringe Ausdehnung gehabt, weil die ohne Hinterlassung von sui sterbenden Erblasser die 
Lücke durch Adoption oder Komitialtestament ausfüllten. War aber jedem Erblasser die Ausfüllung dieser Lücke möglich? War die Vollziehung einer Adoption so leicht? Die Form der datio in adoptionem ergibt diese als etwas erst nach den zwölf Tafeln möglich Gewordnes, und die adrogatio setzt voraus, daßs sich ein Mitbürger findet, der bereit ist, seine Unabhängigkeit mit der Unterwerfung unter die Gewalt des arrogator zu vertauschen. Vor allem aber müssen wir fragen, ob es denn in Rom keine weiblichen und keine unerwachsenen, weder der Adoption noch des Komitialtestamentes fähigen Erblasser gab. Hat es solche gegeben, so kann auch nicht, wie Mitteis meint, jede andre Erbfolge der Kindeserbfolge nachgebildet gewesen sein. War die Kindeserbfolge eine Erbfolge der sui, so hätte sowohl das Weib als der Unerwachsene im Falle seiner der Beerbung durch solche nachgebildeten Beerbung sui zwar nicht während seines Lebens haben, aber durch seinen Tod hinterlassen können. Bei seinen Lebzeiten isi das Verbältnis des Weibes und des Unerwachsenen zu seinen Agnaten dem Verhältnisse des pater familias zu den Seinigen nicht gleich, sondern entgegengesetzt. Hat dieser die Seinigen in seiner Gewalt, so sind jene in gewissem Maße in der Gewalt ihrer Agnaten. Was von den sui nicht gilt, daß sie schon bei Lebzeiten des Erblassers ein Recht an seinem Vermögen haben, das gilt hier vom proximus agnatus, der Verminderungen des eventuell ihm zufallenden Vermögens verhindern kann durch die Verweigerung seiner auctoritas. Hängt die ihm zukommende Verfügung über die familia des Verstorbnen davon $a b$, daß dieser weder testamentarii noch sui heredes hinterläßt, so ist sie nur eine subsidiäre gegenüber einem der Hinterlassung solcher fähigen, dagegen eine primäre gegenüber einem ihrer unfähigen Erblasser. Keinesfalls beruht sie, wie man schon für die gesetzliche Erbfolge angenommen hat, auf dessen vermutetem Willen, da sie namentlich Platz greift gegenüber einem des letzten Willens unfähigen Erblasser.

Nach Mitteis (S. 106) „liegt der Universalsukzession des Erben der Gedanke zugrunde, daß in den Nachkommen nach römischer Auffassung das Individuum fortlebt". Nie kann 
aber das Sterben eines homo sui iuris ohne Hinterlassung von Nachkommen so selten gewesen sein, daß es für die Erbfolge nicht in Betracht kam. Und wenn z. B. ein vaterloses Kind starb und von seinen Geschwistern beerbt wurde, in deren Hand schon bisher das nominell ihm gehörende Vermögen war; soll man dann ihre Erbfolge angesehen haben als eine der Kindeserbfolge nachgebildete und sie selbst als solche, in denen ihr vielleicht im zartesten Alter gestorbenes Brüderchen oder Schwesterchen in derselben Weise fortlebt, wie ein Vater in seinem Sohne? Soll ebenso der Geisteskranke -- auch ein nicht seltner und in den zwölf Tafeln vorgesehener Fall -, der kraft des Gesetzes mit seinem Vermögen in der Gewalt seiner Agnaten stand, durch seinen Tod diese als solche hinterlassen haben, die in demselben Verhältnisse zu ihm stehen wie der Sohn zum Vater, in dessen Gewalt er steht? In Wirklichkeit wird, wenn der Sohn den Vater beerbt, sein Subjektionsverhältnis, das nur einesteils durch die für ihn bestehende Unmöglichkeit, sich der Erbfolge zu entziehen, und andrenteils bis zu seiner Mündigkeit durch die dem Vater mögliche letztwillige tutoris datio und pupillaris substitutio fortwirkt, abgelöst durch das Verhältnis der Sukzession. Sui iuris oder Subjekt einer eignen familia ist er unabhängig von jener. Als des Vaters Erbe vereinigt er aber, wie jeder Erbe, mit seiner familia die familia des Erblassers, die nun ein Bestandteil der seinigen ist, wälirend vorher er selbst ein Bestandteil der familia seines Vaters war. Inwieweit Verschiedenheiten zwischen der auf den Erben übergegangnen familia des Erblassers und der übrigen familia des Erben bestehen, ist eine Frage für sich. Keinesfalls aber bosteht jene als eine von der familia des Erben getrennte. Was bisher des Erblassers war, ist nun des Erben. Freilich behauptet man, er sei Subjekt der ererbten Rechtsverhältnisse nicht als die Person, die er sonst ist, sondern durch die von ihm ererbte Persönlichkeit des Erblassers. ${ }^{1}$ ) Träfe dies zu, so hätte jeder

1) Eine genauere Verfolgung dieser Auffassung enthält der erste Abschnitt meiner Abhandlung über die Stellung des römischen Erben. Nachdem schon 1880 Brinz (Pand. 2.Aul. 3 S. 3) sie glaubte als überwunden bezeichuen zu dürfen, wird sie neuerdings namentlich 
Mensch nicht eine, sondern außer seiner angebornen so viel Persönlichkeiten, als Menschen existieren, die er beerbt hat. Seine ererbten und seine sonstigen Rechtsverhältnisse, sowie die von verschiednen Erblassern ererbten Rechtsverhältnisse wären Rechtsverhältnisse verschiedner Personen. Bekanntlich ist davon keine Rede. Soweit nicht besondre Abweichungen bestimmt sind, ist er Subjekt der von ihm ererbten Rechtsverhältnisse ebenso wie der aus andrem Grunde für ihn existierenden, und Rechtsverhältnisse, die nicht nebeneinander existieren können als Rechtsverhältnisse derselben Person, können auch nicht so existieren, daß er Subjekt des einen als Erbe, des andren unabhängig von seiner Eigenschaft als Erbe ist. ${ }^{1}$ )

Die römischen Quellen wissen nichts von dieser auf oder in den Erben übergegangnen Persönlichkeit des Erblassers. Sie sagen, die hereditas sei nihil aliud quam successio in universum ius, quod defunctus habuerit (Iul. 1. 62 de Reg. Iur.). Die Verschiedenheit der Personen des Erblassers und des Erben wird dadurch nicht verneint, sondern vorausgesetzt. Setzt doch jede successio des Einen in ein Verhältnis, das bisher für einen andren bestand, die Verschiedenheit dieser Subjekte voraus, die sie auch in keiner Weise aufhebt. Wie das Objekt der Sukzession bis zu ihrem Eintritte dem successor fremd war, so ist es von diesem an dem Vorgänger fremd. Mit Recht sagt Brinz (Pand. 1. Aufl. S. 670), daß nach jener Auffassung ,eigentlich nicht sowohl der Erbe in den Nachlaß, als der Erblasser in den

durch Sohm und nun auch durch Mitteis wieder vertreten, weshalb es nicht überflüssig ist, ihr von neuem entgegenzutreten. Vgl, auch mein Buch über natürliche und juristische Personen S. $145 \mathrm{ff}$.

1) Man kann dem Erben die Persönlichkeit des Erblassers zuschreiben neben seiner sonstigen Persönlichkeit oder anstatt seiner bisherigen Persönlichkeit. Im zweiten Falle müßte diese und müßten damit seine bisherigen Schulden, wie durch adrogatio, so auch durch Erbfolge untergehen, während seine Aktiva mit AusschluB der gleichfalls erlöschenden uuübertragbaren Rechte von der Person, die er bisher war, auf die in ihm fortlebende Person seines Erblassers übergingen. Weder von einer solchen Umwandlung, noch von einer Vervielfältigung der Persönlichkeit des zum Erben eines andren Gewordnen zeigen die Wirkungen der Erbfolge eine Spur. 
Erben sukzediert sei". Während man sonst diese Auffassung für spezifisch römisch hält, ist nach $\mathrm{Sohm}$ (der Gegenstand 1908 S. 42) "der Begriff der Nachfolge des Erben in die vermögensrechtliche Persönlichkeit des Erblassers unentbehrlich", um das Wesen der Erbfolge als eines Eintritts, in alle vermögensrechtlich gearteten Rechtsverhältnisse des Erblassers" auszudrücken. Er fügt noch besonders hinzu: „auch in den Besitz, auch in die Schulden." Auf den Besitz erstreckt sich aber die Sukzession des römischen Erben nicht, und auf die Schulden erstreckt sich nicht nur die seinige, sondern auch die Universalsukzession des bonorum emtor, bei der niemand an einen Übergang der Persönlichkeit des Schuldners auf den bonorum emtor denkt und denken kann. Nach Sohm richtet sich die Polemik neuerer Schriftsteller „nur gegen irrige Vorstellungen, die mit diesem Begriff verbunden worden sind“. Gibt es aber eine Nachfolge andrer in meine Rechtslage, so gibt es doch keine Nachfolge solcher in meine Persönlichkeit. Jene gibt es, weil meine Rechtslage die Rechtslage ist, die mir zukam und die, wenn sie auf andre übergegangen ist, zwar nicht mehr die meinige ist, aber mit Ausnahme des Wechsels ihres Subjektes dieselben Merkmale aufweist wie bisher. Dagegen ist meine Persönlichkeit von meiner Person unzertrennlich; denn sie bedeutet nichts andres als daß ich diese Person bin, kann also nicht auf andre Personen übergehen und meine Existenz nicht überdauern.

Von einer ungefähren Identität, wie des Erben mit dem Erblasser, so auch des Sohnes mit dem Vater spricht einmal Justinian (Nov. 48 pr. und l. 11 C. de imp. subst. 6, 26). Was er damit meint, ist nicht sowohl Identität als ein naher $\mathrm{Zu}$ sammenhang, wie er unstreitig sowohl zwischen dem Vater und dem Sohne als dem Erblasser und dem Erben besteht. Jeder Zusammenhang setzt aber die Verschiedenheit der miteinander zusammenhängenden Dinge voraus. Der Zusammenhang des Erblassers mit dem Frben hat das Besondre, daß sie nicht nebeneinander, sondern nacheinander existieren, weil man der Erbe eines andern erst sein kann, nachdem er zu existieren aufgehört hat. Und neben dem Zusammenhange begegnet uns allenthalben der Gegensatz des Erblassers und 
des Erben. Bis auf Justinian kann die obligatio nicht ab heredis persona incipere. Was der Testator dem Erben auferlegt, das legt er nicht sich selbst auf. Gleich Deliktsschulden gehen actiones vindictam spirantes nicht auf den Erben über, und grell ergibt sich seine für das Bewußtsein des Römers bestehende Verschiedenheit vom Erblasser aus der Freilassung und Erbeinsetzung eines Sklaven, die nach Gai. III, 154 der Testator vollzog, um die Schmach der bonorum venditio von sich auf jenen abzuwälzen.

Keine Identität des Erben mit dem Erblasser bedeutet die hereditate iacente platzgreifende Behandlung des Nachlasses, wie wenn er noch Vermögen des Verstorbnen wäre. Wird er, ohne zurzeit Yermögen eines Menschen zu sein, doch behandelt, wie wenn er ein solches wäre, so hat man die Wahl, ihn zu behandeln, wie wenn er noch Vermögen des Erblassers oder wie wenn er schon Vermögen des Erben wäre, und Ulpian erklärt ausdrücklich (1. 34 D. adq. dom.), daß jene Behandlung und nicht diese Platz greife, während im Falle der juristischen Identität des Erben mit dem Erblasser beide zusammenfielen. ${ }^{1}$ )

Mitteis sagt (S. 96): „Nur aus diesem bis in die späteste Zeit unverrückbar gebliebenen Grundgedanken, daß nicht das Vermögen als solches, sondern die Persönlichkeit ererbt wird, aus diesem Gedanken aber auch mit einem Schlag erklären sich die für eine mehr materialistische Denkart rätselhaften Sätze des xömischen Erbrechts." Dieser „Grundgedanke" ist aber ein von keinem römischen Juristen ausgesprochenes Schlagwort, das erst auftaucht zu einer Zeit, zu der man durch die Lehre der Kirche sich gewöhnt hatte, einen zwischen verschiednen Personen bestehenden Zusammenhang als Identität dieser zu bezeichnen. Und da neben und hinter dieser angeblichen Identität doch immer wieder die wirkliche Verschiedenheit sich geltend macht, so hat jenes Schlagwort das Bequeme, daß man, was zu ihm 3t, auf die juristische Identität der verschiedenen Personen, was dagegen nicht paßt, auf ihre trotzdem bestehende faktische

1) Derselbe Ulpian sagt in 1. 1 D. de rel. 11,73 qui propter funus aliquid impendit cum defuncto contrahere creditur, non cum herede. 
Verschiedenheit zurückführen kann. Mit Recht sagt Windscheid (Pand. § 528 Anm. 7): „Die vermögensrechtliche Persönlichkeit des Erblassers als fortlebend denken, heißt, den Erblasser in vermögensrechtlicher Beziehung als fortlebend denken, und warum soll er als fortlebend gedacht werden, da er doch in Wirklichkeit gestorben ist?" Wenn in gewissem Sinne der Erblasser in seinen Erben fortlebt, so bedeutet dies nicht, daß seine Persönlichkeit auf andre Menschen übergegangen wäre, sondern, daß andre Personen ihn als einen nicht mehr Lebenden ersetzen, was namentlich, aber keineswegs ausschließlich, durch solche geschehen kann, deren Existenz und Persönlichkeit von der seinigen abgeleitet ist.

Wenn Mitteis sagt (S. 93): "Universalsukzession und Abstammung fallen ursprünglich zusammen", so gilt dies schon deshalb nicht, weil die Abstammung mit der Entstehung des Abkömmlings, dagegen die Universalsukzession erst mit dem Tode des Erblassers eintritt. Dagegen ist die Abstammung von diesem ein Hauptgrund, aber nie der einzige Grund seiner Beerbung. Sein sogenanntes Fortleben durch den Erben ist nicht eine Fortdauer, aber eine Nachwirkung seines Lebens als eines untergegangnen, für die er

1. selbst gesorgt haben kann

a) durch Fortpflanzung seines Stammes, dessen Fortsetzern als den ihm am nächsten stehenden Menschen seine Ersetzung zukommt, wenn er keine andre Bestimmung getroffen hat;

b) unmittelbar durch Testament, dessen Wirkung eine verschiedne ist im Falle der Erbeinsetzung seiner Gewalt unterworfner und andrer Menschen. Während er diesen seine Ersetzung nur antragen kann, so daß sie von ihrem Willen abhängt, so kann er sie jenen als eine von ihrem Willen unabhängige auferlegen. In dieser Beziehung besteht kein Unterschied zwischen den Objekten seiner Familiengewalt und Fortsetzern seines Stammes und den Bestandteilen seines Vermögens oder seinen Sklaven, zwischen denen dagegen der Unterschied besteht, daß die einen die ihm am nächsten stehenden und ihn auch ohne Testament beerbenden Menschen, dagegen die andren solche Menschen sind, die 
erst durch sein Testament zu Rechtssubjekten erhoben werden müssen, um zugleich zu seinen Erben ernannt werden zu können. Von jedem andren heres unterscheidet sich aber der testamentarius, sei er nun necessarius oder voluntarius, dadurch, daß mit der Ersetzung des Erblassers durch ihn sich verbindet die für den Erblasser bestehende Möglichkeit weiterer letztwilliger Bestimmungen. Wirkt durch jede Erbfolge das Leben des Verstorbnen nach, so ist nur im Falle der testamentarischen Erbfolge diese Nachwirkung eine Geltung seines Willens als eines solchen, der nicht nur die Erbfolge bestimmt, sondern auch durch weitere Bestimmungen den Erben binden kann. Er bindet diesen nicht wegen seiner angeblichen Identität mit dem Erblasser, durch die, wenn sie zuträfe, dessen Wille sein Wille wäre, sondern als ein fremder vermöge des fremden durch seine Erbfolge zur Geltung gelangten Testamentes zu Recht bestehender Wille. Auf deutlichste zeigt dies das legatum per damnationem. Niemand kann sich selbst gegenüber eine damnatio vollziehen, und wäre sie dem Erben gegenüber vollzogen als dem Fortsetzer der Persönlichkeit des Erblassers, wie könnte sie dann im Falle mehrerer Erben anders vollzogen werden als gegenüber allen?

2. Hat der Verstorbne für scine Ersetzung nicht selbst gesorgt -- und ein solcher, der weder sui heredes noch ein Testament zu hinterlassen vermag, kann gar nicht sclbst für sie sorgen -, so überträgt das Gesetz dic Sorge dafür seinem nächsten Agnaten und in Ermanglung von Agnaten seinen Gentilen. Sind meine sui die Fortsetzer meines eignen Stammes, so sind meine Agnaten und Gentilen solche, die mit mir den Stamm desselben Stammvaters fortsetzen. Solange der Stammvater lebt, sind die Fortsetzer seines Stammes miteinander verbunden durch ihre gemeinsame Unterwerfung unter seine Gewalt. Durch seinen Tod erlischt diese enge Verbindung. Es bleibt aber als ihre Nachwirkung eine weitere. Sie zeigt sich namentlich, wenn ein Mensch, der keinen pater familias hat, rechtlicher Selbständigkeit unfähig ist. Sein rechtliches Dasein erfährt die Ergänzung, deren es aus jenem Grunde bedarf, durch Vormundschaft. Diese kommt teils bezüglich der impuberes und mulieres in Er- 
manglung eines vom verstorbnen pater familias ernannten testamentarius tutor, teils bezüglich der furiosi und prodigi schlechthin den Agnaten und Gentilen zu. Der ihnen zukommenden Sorge für die Ergänzung des rechtlichen Daseins eines Stammgenossen entspricht die ihnen zukommende Sorge für die Beerbung des ohne Hinterlassung eines testamentarius oder suus heres Verstorbnen. Der enge Zusammenhang beider Verhältnisse zeigt sich auch darin, daß gleich der legitima tutela die legitima hereditas bezüglich eines impubes ausgeschlossen sein kann durch Testament des verstorbnen pater familias und daß gleich der legitima hereditas die legitima tutela ein Objekt der in iure cessio ist.

Im Gegensatze zu jeder andren ist die legitima hereditas weder unmittelbar noch mittelbar durch den Willen des Erblassers gegeben und auch durch das Gesetz nicht etwa nur dem proximus adgnatus für seine Person angetragen, sondern seiner Verfügung überlassen. Die danach dem Gesetze eigne Gleichgültigkeit gegen die Person des Erben kann übrigens auch der Testator dadurch betätigen, daß er einen fremden Sklaven zum Erben einsetzt, so daß sein Herr die Erbschaft sowohl durch seine Freilassung ihm selbst als durch seine Zuwendung beliebigen Dritten zuwenden kann. Wie die Freilassung und Erbeinsetzung eines eignen Sklaven benutzt wurde, um auf sein unschuldiges Haupt die Schmach der wegen der Schulden des Testators stattfindenden bonorum venditio abzuladen, so gewährte die Erbeinsetzung eines fremden Sklaven die Möglichkeit, die Erbfolge zu einem Gegenstande beliebiger Verfügung seines Herrn zu machen, und auch diese Möglichkeit stimmt wenig zur Auffassung der Erbfolge als einer Fortsetzung der Persönlichkeit des Verstorbnen. Als etwas Bekanntes und nicht weiter Auszuführendes erwähnt Mitteis (S. 94) den Zusammenhang der Vererbung der Opferpflicht auf den Sohn und Enkel "mit den spekulativen Vorstellungen von der Unsterblichkeit der Seele und dem Ahnenkultus" (S. 94). Mit diesen Vorstellungen ist aber, wie ich schon in meinem Buche über natürliche und juristische Personen (S. 146) betont habe, die Annahme der auf Überlebende übergehenden Persönlichkeit Verstorbner unvereinbar. $\mathrm{Da} ß$ wir in unsren Kindern fortleben, ist keine Unsterblich- 
keit der Seele, und der Ahnenkultus beruht nicht auf einer Identifizierung, sondern auf einer Entgegensetzung der Vorfahren und Nachkommen.

Tritt uns so die Stellung des römischen Erben von Anfang an als eine solche entgegen, die zwar auf einem Familienverhältnisse beruhen kann, aber nicht ein Familienverhältnis ist und ihre dem römischen Erblasser am meisten am Herzen liegende Bedeutung, dic Geltung seines Willens über seinen Tod hinaus zu vermitteln, nur dann hat, wenn sie selbst auf seinem letzten Willen beruht, so ist dadurch nicht ausgeschlossen, daß es eine Zeit gegeben hat, zu der in Rom die Erbfolge ausschließlich Familienerbfolge war. Mit Unrecht leitet man aus der ältesten Testamentsform ab, das Testament sei ursprünglich cine lex im Sinne eines iussus populi gewesen. Das aber ergibt jene Form, daß es nicht älter ist als der römische Staat, wogegen die Grundzüge des römischen Privatrechts unstreitig älter sind. Nichts ist spezifisch römischer als dic jedem andren Volke fremde Trennung des ius publicum und privatum, die so erstaunlich ist, daß ein Ilistoriker wie Fiduard Meyer (Gesch. des Altertums 2. Aufl. I, 51) von der "Absurdität" der neben seiner privatrechtlichen Subjektion unter den Hausvater bestehenden staatsrechtlichen Gleichstellung des Haussohns mit dem Hausvater spricht. Die eine und die andre kann nicht derselben Wurzel entsprungen sein, und die Wurzel der privaten Gewalt des Hausvaters muß jenseits des römischen Staates liegen. Nichts ist unrichtiger als die Annahme von Greiff (De l'origine du testament Romain 1888 S. 46), die Organisation der römischen Familie sei eine militärische und sie sei „comme une division quasi militaire du peuple, confiée au commandement du pater familias". Wie soll eine Organisation eine militärische sein, die sich nicht nur auf Männer, sondern auch auf Weiber und Kinder erstreckt und nach der dem greisen, keiner militärischen Leistung mehr fähigen Hausvater die erwachsenen Söhne ebenso unselbständig gegenüberstehen wie die Ehefrau, die Töchter und die Kinder?

Haus und Staat, Hausgewalt und Staatsgewalt ist in Rom durchaus zweierlei. Die römische familia kann nicht auf dem Boden des römischen Staates entstanden sein. Im 
Staate ist sie diesem untergeordnet, aber zugleich noch in höherem Grade als vorher ein Gebiet der Macht des pater familias als einer nicht mehr wie bisher durch die gens beschränkten. Erst im Staat und durch dessen Vermittlung erstreckt sich die Macht des pater familias über seinen Tod hinaus und emanzipiert sich dadurch die Erbfolge vom Familienzusammenhange. Und das Spezifische der römischen Erbfolge ist nicht ihr Ursprung aus dem Familienzusammenhang, sondern ihre Ablösung von diesem. War ursprünglich Familienbeziehung der einzige Erbgrund und ist sie für die Becrbung eines intestatus Erbgrund geblieben, so ist doch seit dem Aufkommen des Testamentes dieses der primäre Erbgrund, was uns allenthalben als römische Anschauung entgegentritt. Die Entstehung dieser durch das Testament bewirkten Ablösung der Erbfolge vom Familienzusammenhange ist uns ebensowenig zugänglich wie die Entstehung der römischen Entgegensetzung des privaten und öffentlicben Rechtes. Durch die für das römische Recht nicht nur nicht bezeugte, sondern allem, was wir wissen, widersprechende Auffassung des Testamentes als eines selchen, das ursprünglich einen Familienzusammenhang begründete, kann sie aber nicht erklärt werden. Insbesondere läßt die Ausschließlichkeit der testamentarischen Erbfolge sie-als eine die kraft des Familienzusammenhangs platzgreitende Erbfolge nicht etwa nachahmende oder ersetzende, sondern ausschließende erscheinen, wogegen die Personen, für die sie Platz greift, sowohl andre als dieselben sein können, wie im Falle dieser.

Appleton (Le testament Romain etc. 1903 S.95) leitet die Möglichkeit der heredis institutio eines suus aus der Möglichkeit seiner exheredatio ab, die „le pendant naturel et nécessaire de l'institution d'un étranger" sei. Ließe sich aber erklären, daß angesichts der ohne das Testament Platz greifenden Erbfolge der sui andre Erben in ihm nicht ernannt werden konnten, ohne daß die Erbfolge der sui entweder durch ihre exheredatio beseitigt oder durch ihre institutio als eine neben der Erbfolge jener Platz greifende bestätigt wurde, so wäre es doch unerklärlich, daß ein Testator, der keine andren Erben als die ihn auch ohne Testament beerbenden sui haben und etwa nur die verschiednen Be- 
standteile seiner Habe unter sie verteilen wollte, dies nicht tun konnte, ohne sie zu Erben einzusetzen. Ist danach irgendeine letztwillige Bestimmung des pater familias nur möglich, wenn seine Beerbung eintritt als eine durch seinen letzten Willen bestimmte, so kann die gleich jeder andren diese Möglichkeit begründende Erbeinsetzung der sui keine bloße Bestätigung ihrer Erbfolge als einer auch ohne das Testament platzgreifenden gewesen sein, muß vielmehr den in Ermanglung eines Testamentes platzgreifenden Erbgrund der Familienangehörigkeit durch den Erbgrund des Testamentes verdrängt haben, dessen im Gegensatze zu andren Fällen vom Willen des Eingesetzten unabhängige Wirksamkeit nicht auf jener, sondern lediglich auf der dem suus mit dem servus gemeinsamen Subjektion unter den pater familias beruhte.

Die Gleichgültigkeit des Testaments gegen die Eigenschaft des Eingesetzten, auch ohne dieses zur Erbfolge berufen zu sein, und die dieser Eigenschaft nicht neben dem Testament, sondern ausschließlich in Ermanglung eines solchen zukommende rechtliche Bedeutung ist das Gegenteil des Verhältnisses, das zwischen der ohne Testament stattfindenden Familienerbfolge und der Testamentserbfolge bestehen müßte, wenn diese ein Surrogat, eine Abart oder eine Modifikation jener wäre. Jede Auffassung, die im Komitialtestamente ein Gesetz sieht, das für den einzelnen Fall die allgemeinen Normen über die Erbfolge ändert oder ergänzt ${ }^{1}$ ), widerspricht nicht nur dem primären und exklusiven Charakter der römischen Testamentserbfolge, sondern auch der römischen grundsätzlichen Verschiedenheit zwischen dem öffentlichen und Privatrechte. Man sagt vielfach, wenn auch die Römer keine Erinnerung an die Eigenschaft des Testamentes als eines iussus populi gehabt haben, so müsse es doch ein solcher gewesen sein wegen seines über den Inhalt andrer privater Verfügungen

1) Diese Auffassung vertritt insbesondre als die einzige im Lichte der vergleichenden Rechtswissınschaft nögliche La mbert, La tradition Romaine sur la succession des formes du testament devant l'histoire comparative 1901. Vgl. namentlich S. 29: , une décision des comices, corrigeant ou complétant... les règlẹs habituelles de la succession ab intestat."

Zeitschrift fïr Rechtsgeschichte. XXX. Rom. Abt. 
weit hinausreichenden Inhaltes. Kann man aber nicht mit gleichem oder größerem Rechte fragen, ob es mit der römischen grundsätzlichen Unterscheidung der Machtsphäre des Staates und des pater familias sich verträgt, daß je die Verfügung über dessen Nachlaß ein Staatsgesetz gewesen wäre?

Selbstverständlich war die Eigenschaft des Testamentes, nur vor dem in seiner verfassungsmäBigen Gliederung zusammentretenden populus vollzogen werden zu können, nicht bedeutungslos. Nur in seiner doppelten Eigenschaft als pater familias und Glied des populus konnte der Römer ein solches errichten, und die Assistenz des populus bei dessen Errichtung gewährleistete ihm dessen Geltung, die durchzusetzen im Gegensatze zu andren Rechtsgeschäften ihm selbst nicht mehr möglich war. Daß aber je dessen Inhalt nicht als Inhalt seines vom Staate zugelassenen und anerkannten Willens, sondern als Inhalt des Staatswillens gegolten hätte, davon findet sich keine Spur. Insbesondere treten uns die Worte heres esto, die auf das Komitialtestament zurückgehen müssen, als solche entgegen, die zwar ebenso lauten wie die Worte eines befehlenden Staatsgesetzes, aber die diesem für jeden Bürger eigene Verbindungskraft nur für die der Gewalt des Testators unterworfenen Menschen haben wegen der nur für diese, für sie aber auch noch nach seinem Tode maßgebenden Bedeutung seines Willens, wogegen andre durch Testament zu seinen Erben ernannte Menschen seine Erben nicht worden ohne ihre erst nach seinem Tode mögliche Zustimmung. Das Testament ist nicht, wie jedes Staatsgesetz und wie insbesondre auch die adrogatio, eine rogatio eines Magistrates an den populus. Es ist aber, soweit es Menschen zu Erben ernennt, die nicht der Gewalt des Testators unterworfen sind, eine rogatio des Testators an diese, die erst mit seinem Tode zu Recht besteht. Den Objekten der eignin Gewalt gegenüber eine Verfügung, ist das heres esto andren gegenüber eine Bitte, deren Erfülllung nicht eine Unterwerfung unter die Gowalt ihres nicht mehr existierenden Urhebers, sondern ein Freundesdienst, sowie eine Annahrne der durch sie dem zum Erben Erbetenen erwiesenen Ehre ist. Wenn nach Hegel (Grundlinien der Philosophie des Rizhts 2. Aufl. 1840 S. 239) 
„die sogenannte Familie der Freundschaft, welche das Testament hervorbringt, nur in Ermanglung der näheren Familie der Ehe und Kinder eintreten kann, " so ist den Römern die Eigenschaft der Erbeinsetzung als einer einem Freunde erwiesenen Ehre und ihrer Annahme als eines Freundesdienstes geläufig, aber der Gedanke an eine dadurch begründete Familienbeziehung gänzlich fremd.

\title{
IV. \\ Weitere Studien zum Texte der Digesten.
}

\author{
Von \\ Herrn Professor Dr. Fr. Eisele \\ in Freiburg j. Br.
}

Das Folgende kann als fünfter Beitrag zur Erkenntnis der Digesteninterpolationen (vgl. Bd. 18 dieser Zeitschrift S. 1 ff.) gelten. Es mußte eine andere Überschrift gewählt werden, weil unter die nach ihrer Reihenfolge in den Digesten aufgeführten interpolationsverdächtigen Stellen auch einige Emendationen des uns überlieferten Textes des Gesetzbuchs Justinians eingereiht sind. Bezüglich der ersteren bemerke ich noch, daß sie nur ein Teil derjenigen sind, die ich seit dem Erscheinen meines letzten Beitrags mir als interpolationsverdächtig notiert habe. Von diesen habe ich eine ziemliche Anzahl weggelassen, weil mir bei genauerer Prüfung die Gründe für eine Interpolationsannahme nicht hinreichend zu sein schienen, andre deshalb, weil die Interpolation schon von andrer Seite konstatiert worden war, bzw. inzwischen konstatiert worden ist. Diese Stellen mit Nennung der betreffenden Autoren und dazugehörigen Literaturnachweisungen anzugeben, würde wenig Wert haben.

2, 14 1. 7 \& 16 Ulp. I. 4 ad ed.

Et generaliter quoties pactum a iure communi remotum est, servari hoc non oportet: nec legari nec iusiurandum de hoc adactum, ne quis agat, servandum Marcellus 